\title{
The sociolinguistics of /I/ in Manchester
}

DOI:

10.1515/lingvan-2020-0074

\section{Document Version}

Final published version

Link to publication record in Manchester Research Explorer

\section{Citation for published version (APA):}

Turton, D., \& Baranowski, M. (2021). The sociolinguistics of /// in Manchester. Linguistics Vanguard. https://doi.org/10.1515/lingvan-2020-0074

\section{Published in:}

Linguistics Vanguard

\section{Citing this paper}

Please note that where the full-text provided on Manchester Research Explorer is the Author Accepted Manuscript or Proof version this may differ from the final Published version. If citing, it is advised that you check and use the publisher's definitive version.

\section{General rights}

Copyright and moral rights for the publications made accessible in the Research Explorer are retained by the authors and/or other copyright owners and it is a condition of accessing publications that users recognise and abide by the legal requirements associated with these rights.

\section{Takedown policy}

If you believe that this document breaches copyright please refer to the University of Manchester's Takedown Procedures [http://man.ac.uk/04Y6Bo] or contact uml.scholarlycommunications@manchester.ac.uk providing relevant details, so we can investigate your claim.

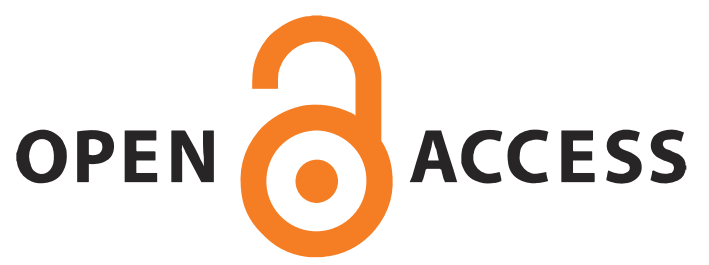




\title{
Danielle Turton* and Maciej Baranowski The sociolinguistics of / $/$ in Manchester
}

https://doi.org/10.1515/lingvan-2020-0074

Received August 13, 2020; accepted March 1, 2021; published online October 22, 2021

\begin{abstract}
This paper presents a study of sociophonetic variation in the lateral approximant /l/ in Manchester, UK. We know little about how English laterals pattern sociolinguistically, despite them having been subject to extensive investigation in the phonetic literature. We present acoustic measures taken from interviews with 96 speakers from the city, stratified across five socioeconomic classes, spanning 99 years of birthdates (1907-2006). We demonstrate that word-initial /1/ is becoming darker in apparent time: younger speakers have darker /1/s. There is, however, no evidence that the allophonic status of /1/ is changing, with /1/ in all positions becoming darker. There is a monotonic relationship with social class: the higher the social class, the lighter the /1/, with some middle-class speakers showing potential of an allophonic distribution. We find an effect of ethnicity, with white speakers having darker /1/s in comparison to Black and Pakistani Mancunians. Overall, our findings are a novel contribution to the understanding of the sociophonetics of English laterals and provide new evidence of social patterning and the allophonic status of /l/ in this variety.
\end{abstract}

Keywords: English; language variation and change; laterals; sociophonetics; sound change

\section{Introduction and background}

The realisation of English /1/ has been the subject of a vast number of phonetic and phonological studies in recent years, due to its articulatory complexity and debates around the allophonic status of light and dark counterparts (Boersma and Hayes 2001; De Decker and Mackenzie 2017; Lee-Kim et al. 2013; Sproat and Fujimura 1993; Turton 2017). Syllable-based accounts generally state that light [1] occurs in onset position, e.g. love, and dark [1] in coda position, e.g. fall, although this generalisation does not apply across all varieties of English. Compared to light [1], the dark variant is reported as having a delayed or reduced tongue tip gesture. In terms of sociolinguistic studies of non-laboratory speech within a given speech community, very few quantitative instrumental studies exist. Thus, we know little about the sociolinguistic conditioning of the darkness of /1/ in varieties of English, and whether this is stable or changing. The present study is a large-scale investigation into the sociophonetics of /1/ in Manchester, UK. As this is a variety which is commonly reported to have dark realisations of /1/ in all positions (Kelly and Local 1986; Carter 2002; Beal 2008; Turton 2014; Turton 2017; Kirkham et al. 2019), our investigation pays due consideration to both social and linguistic factors affecting pronunciation.

The common description of English /1/ as outlined above is typical of accents such as Received Pronunciation (henceforth RP), where word-initial love-type tokens of /1/ achieve full tongue-tip contact and wordfinal fall-types exhibit the described delayed or reduced tongue-tip gesture. In addition to the potential presence of two discrete allophones, phonetic studies have shown that darkness is on a continuum, with darker variants having an earlier or backer tongue dorsum gesture articulatorily, and a reduction in the F2-F1 difference acoustically (De Decker and Mackenzie 2017; Gick et al. 2006; Lehiste 1964; Sproat and Fujimura 1993; Turton 2014; Yuan and Liberman 2009, 2011).

Although the acoustics and articulation of /1/-darkness have been studied comprehensively in phonetics, sociolinguists have largely focussed on the categorical vocalisation of /1/ (e.g. Ash 1982; Hall-Lew and Fix 2012;

\footnotetext{
*Corresponding author: Danielle Turton, Department of Linguistics and English Language, Lancaster University, Bailrigg, Lancaster, LA1 4YW, UK, E-mail: d.m.turton@lancaster.ac.uk

Maciej Baranowski, School of Arts, Languages and Cultures, The University of Manchester, Manchester, UK, E-mail: maciej.baranowski@manchester.ac.uk
}

Ә Open Access. @ 2021 Danielle Turton and Maciej Baranowski, published by De Gruyter. @() BY This work is licensed under the Creative Commons Attribution 4.0 International License. 
Horvath and Horvath 2001, 2002; Johnson and Britain 2007; Tollfree 1999; Tollfree 1999). Aside from Pratt's (2020) recent study of "tech" students in San Francisco, the main exception to this trend is a range of studies on ethnic minority groups in North America (Newman 2010; Van Hofwegen 2009, 2011), as well as work on bilinguals in the British Isles (Khattab 2002, 2011 on Arabic-English bilinguals in Yorkshire; Morris 2013, 2017 on Welsh-English bilinguals and Nance 2013, 2020 on Scottish Gaelic bilinguals in Glasgow). However, in terms of factors such as change in progress or the role of socio-economic status, we know almost nothing about the sociolinguistic conditioning of the gradient darkness of /1/ in varieties of English.

The present study seeks to investigate the sociolinguistic conditioning of /1/ in Manchester by analysing acoustic data from sociolinguistic interviews. By considering the effects of age, social class and gender, alongside linguistic effects such as phonetic and phonological context, our study provides new evidence of sound change in progress, and its complex relationship to allophonic status. As mentioned, Manchester $/ 1 /$ has is shown to be dark in all positions. This is not only a phonetic claim, but the claim has also been made in reference to the allophonic status of light versus dark /1/ (Turton 2014, 2017) i.e., that Mancunians just have one allophone of $/ 1 /$, which happens to be dark phonetically. However, there is some evidence that this distribution may be conditioned by social class: the lack of positional variation may be characteristic of working class speech (Turton 2014; Turton and Baranowski 2015).

That said, there is a possible discrepancy between dialect literature reports and more recent phonetic studies of northern areas of England today. The linguistic Atlas of England (Orton et al. 1978; based on the 1950s data from the Survey of English dialects (SED); Orton 1962) maps the entirety of the north as having light realisations in word-final position (see Figure 1), yet more recent observations provide evidence that Lancashire and Yorkshire have dark realisations in all contexts (Carter 2002). An example of such conflicting accounts comes from nearby Sheffield: Stoddart et al. (1999) report Sheffield /1/ impressionistically as being all-light (based on SED data from the 1950s plus contemporary data), but Kirkham (2016) reports acoustic data showing it is all-dark.

There are two potential explanations for these differences: fieldworker coding or change over time. As Wells (1982) observed, northern varieties lack the sharp light/dark /1/ allophony found in the south, resulting in northern word-final /1/ sounding potentially lighter than, say, RP. That is, these varieties could have had one

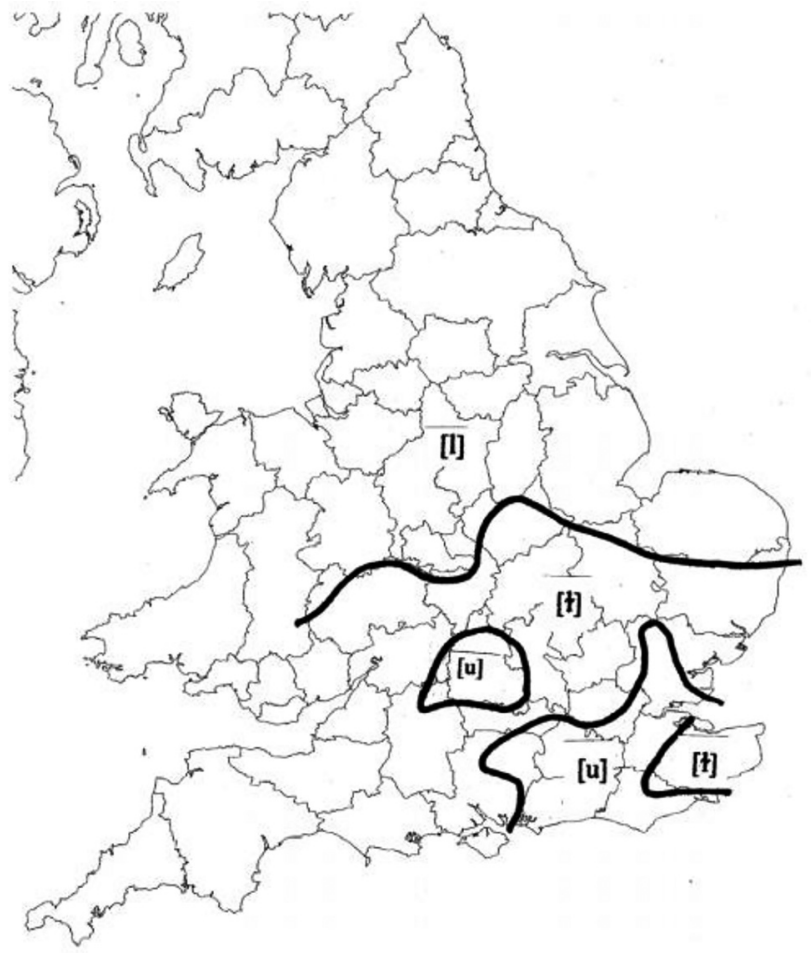

Figure 1: From The linguistic Atlas of England (Orton et al. 1978), mapping word-final / / as light in the north of England in the 1950 s ([u] represents vocalised /l/). 
allophone with an intermediate phonetic status, which SED fieldworkers may have perceived as light. The other possible explanation is that a change has occurred over the past 70 years. Given the gradience of darkening, it is conceivable that $/ 1 /$ has changed very slowly and imperceptibly. ${ }^{1}$

The primary aim of the present study is to investigate the sociolinguistics of Manchester /l/ over a span of 99 years, considering year of birth, social class, gender and ethnicity as predictors of variation and change, alongside contextual factors. The secondary aim is to contribute to the debate on the allophonic status of light and dark variants. Using naturalistic data from a large sociolinguistic interview corpus offers the benefit of observing change over time and within carefully stratified social groupings, providing new insights to this variable, for which most of our knowledge comes from laboratory data.

\section{Methodology}

The paper is based on the speech of 96 Mancunians recorded in sociolinguistic interviews, aiming at eliciting informal spontaneous speech (Labov 1984; Tagliamonte 2006). The current sample of 94 speakers, recorded between 2008 and 2014, is supplemented with two interviews conducted in 1971 in Manchester by William Labov (birth dates 1907 and 1922); as a result, the years of birth of the informants range from 1907 to 2006 (or 1927 to 2006 in the contemporary set). The sample covers the socio-economic range of the city, with five social classes, from lower working to upper middle, operationalised in terms of occupational levels; occupation has recently been shown to be the best single indicator of socio-economic status for a number of other linguistic variables in Manchester (Baranowski and Turton 2018). The sample represents the three main ethnic groups in Manchester with 67 white speakers, 16 Pakistani speakers, and 13 Black Caribbean speakers, all born and raised in Manchester.

The interviews were forced-aligned in FAVE (Rosenfelder et al. 2014) and all tokens of /1/ were measured automatically in terms of F1 and F2 with a Praat script (Boersma and Weenink 2017), resulting in a grand total of 53,943 tokens of /1/; we use the midpoint of F2-F1 as an indicator of /1/ darkness. For most of the analysis, we focus on word-initial tokens only $(n=15,038)$ but do combine word-initial and word-final tokens in parts of the analysis $(n=28,455)$. Our purely acoustic methodology cannot account for vocalised $/ 1 / \mathrm{s}$, which require auditory or articulatory confirmation (Hall-Lew and Fix 2012; Strycharczuk et al. 2020). Unlike many British varieties where vocalisation of /1/ is on the rise (Britain 2009; Foulkes and Docherty 1999), this is not a typical feature of Manchester speech, although we do note some gradient vocalisation in a few of our younger middle class speakers.

Linear mixed-effects regression models were run on the difference between F2 and F1 as the acoustic correlate of darkness in word-initial position using the lme4 package in $R$ (Bates et al. (2015); speaker and word were included as random effects). $t$-values $> \pm 2$ are taken as significant. F2-F1 is partially self-normalising and following Turton (2014) and Kirkham et al. (2019) we took no further steps to normalisation. Potential predictors and interactions were tested by comparing models with and without by likelihood ratio tests. All numeric variables were centred around the mean and duration was log transformed.

\footnotetext{
1 In early episodes of the world's longest-running TV Soap Opera Coronation Street, set in Manchester, older characters, e.g. Elsie Tanner, have noticeably lighter /1/s than present-day Mancunians. However, they do not have a characteristic RP-like light/l/. It is difficult to describe them, but it is possible that they may have clearer tongue tip contact at the onset whilst maintaining a backer tongue dorsum retraction throughout. Another interesting observation from 1970s episodes is that characters who are still in the soap today (e.g. Gail Platt) impressionistically may have had lighter /1/s then, than they do now. Elliott (2000) conducted this kind of study on American English rhoticity in individual actors' lifespans, finding that actors moved with the ongoing change in the country to the reinstatement of post-vocalic /r/; this could be a subject ripe for study.
} 


\section{Results and discussion}

For the main part of our analysis, we focus on word-initial /1/ tokens. This is the context offering the most potential in terms of new sociolinguistic variation, as this is the context in which Mancunians (and northerners in areas like Lancashire and Yorkshire) differ most from standard or southern British English accents. Table 1 shows the best mixed-effects linear regression model of predictors on the F2-F1 difference, which includes social class, age, gender, ethnicity, the height of the following vowel (high, mid, low), the preceding context (vowel, consonant, pause), and the duration of the /1/ (log transformed). Frontness of the following vowel was tested, but it contributed nothing to the model and we decided to omit it. Recall that lighter $/ 1 / \mathrm{s}$ have a higher F2-F1 difference and darker variants have a lower F2-F1 difference. Although the main focus is on initial /1/, at regular points during the discussion, we note the findings of various analyses which include both word-initial and word-final $/ \mathrm{l} / \mathrm{s}$, in order to address the question of allophonic status. Whilst being aware of the difficulties in ascribing a categorical allophonic distinction from comparing initial and final contexts as we do here (see Turton 2017), we suggest that such differences could be indicative of such a presence.

Note that we avoid including initial and final tokens together in the analysis. This is because of the difficulty of summarising the preceding and following contextual and phonetic information within the same model. For example, for word-initial /l/, the main contextual factors are whether the preceding sound is a vowel, consonant or pause, but for a word-final $/ 1 /$, it is the quality of the preceding vowel. Because we know surrounding context has a large influencing effect, it is important to have the information coded accurately in the model and thus warrants separating out these word positions.

\subsection{Social factors}

The potential for change over time in Northern English /1/ was raised earlier in the paper, where we noted that older dialect reports from 1950s data (Orton et al. 1978) show light /1/s in the north, but more recent phonetic research shows the opposite for some parts of the north i.e. dark variants in all positions (Carter 2002; Kirkham 2016; Turton 2017). We considered whether this discrepancy was due to earlier fieldworker difficulty in transcribing the sound

Table 1: The best mixed-effects model for initial /l/s. Higher estimates reflect lighter $/ \mathrm{l} / \mathrm{s}, t$-values $> \pm 2$ are taken as significant. Class 1 , lower working; 2 , upper working; 3 , lower middle; 4, middle middle; 5 , upper middle.

\begin{tabular}{|c|c|c|c|c|c|}
\hline Level & Estimate & Std. error & $t$ value & $\begin{array}{r}\text { Mean } \\
\text { F2-F1 }(\mathrm{Hz})\end{array}$ & $n$ \\
\hline Class (baseline 1) & & & & 837 & 2,841 \\
\hline Class 2 & 55.04 & 43.03 & 1.279 & 885 & 3,829 \\
\hline Class 3 & 32.87 & 43.24 & 0.7603 & 838 & 4,887 \\
\hline Class 4 & 97.26 & 46.34 & 2.099 & 896 & 2,925 \\
\hline Class 5 & 101.7 & 62.46 & 1.629 & 985 & 848 \\
\hline Birth year & -3.193 & 0.8083 & -3.951 & & \\
\hline Gender (baseline female) & & & & 836 & 8,942 \\
\hline Gender male & 87.82 & 29.95 & 2.932 & 911 & 6,388 \\
\hline Ethnicity (baseline Black) & & & & 1,064 & 1,555 \\
\hline Ethnicity Pakistani & -43.05 & 55.05 & -0.7819 & 975 & 3,479 \\
\hline Ethnicity white & -259.5 & 45.02 & -5.764 & 803 & 10,296 \\
\hline Following vowel height (baseline high) & & & & 1,028 & 2,790 \\
\hline Following mid vowel & -163.8 & 18.39 & -8.907 & 889 & 2,936 \\
\hline Following low vowel & -249.7 & 18.68 & -13.37 & 816 & 9,604 \\
\hline Context (baseline post-consonant) & & & & 826 & 7,219 \\
\hline Utterance initial & 160.2 & 8.424 & 19.02 & 981 & 2,813 \\
\hline Post-vowel & 34.34 & 7.315 & 4.695 & 867 & 5,298 \\
\hline Duration (log) & -109.1 & 6.339 & -17.21 & & \\
\hline (Intercept) & -51.7 & 57.07 & -0.9059 & & \\
\hline
\end{tabular}


accurately by ear or, alternatively, that the /1/ has changed since the dialect data was collected. Our results provide support for the latter possibility i.e., /1/ has become darker over time in Manchester. Our model indicates that speakers with an earlier birth year have lighter initial /l/s, with a trend in apparent time towards darker initial /l/s for speakers born more recently (see Figure 2). The picture remains the same when we exclude the two speakers interviewed in the 1970s and use age as a predictor instead of birth year. The trend in the opposite direction seen for the youngest speakers, that is, those born since the 1990s is likely not an indication of a reversal of the change, but rather a reflection of the conservative behaviour of children, reflecting their parents' generation's speech, resulting in what is often referred to as the adolescent peak (Bermúdez-Otero 2020; Labov 2001; Tagliamonte and D'Arcy 2009); a similar pattern has also been found in the fronting of the Goose vowel in Manchester (Baranowski 2017).

In any case, even the older speakers with lighter initial /1/s do not approach the level of lightness found in Received Pronunciation or speakers from the South East of England. For example, the average F2-F1 difference in initial /l/s for speakers born earlier than 1959 is 949 Hz, but in Kirkham et al.'s (2020) recent study, Londoners average around $1,100 \mathrm{~Hz}$ for initial /1/ today (data available from Kirkham 2020).

This change towards a darker initial / $1 /$ over time raises an interesting question. Is this darkening of initial /1/ responsible for the claimed lack of allophonic distinction (where, if present, word-initial /1/s are lighter than word-final ones; Turton 2014, 2017) in Manchester i.e., have younger speakers collapsed a previously existing distinction resulting in dark /1/ in all positions? We revisit this question after first considering social class.

The social class results reveal a near-monotonic trend: the higher the social class, the lighter the initial /l/, as seen in the estimates of the F2-F1 difference in Table 1. Although comparisons between individual classes do not reach statistical significance, the inclusion of class overall is significant by likelihood ratio test. Moreover, the estimates indicate that the trend is unlikely to be accidental in that we have a near-monotonic pattern. In terms of initial and final position, additional models reveal that social class 1 (the lower working class) show next to no difference between initial and final /1/ realisations, whereas 5 (the upper middle class) have fairly light initial $/ 1 / \mathrm{s}$. We suggest that this relative difference could be used as a proxy for an allophonic distinction in the upper middle class. Evidence for this comes from a separate regression looking only at wordfinal $/ 1 / \mathrm{s}$, where social class is not significant. This means that all social classes have roughly equal word-final /1/ darkness, but a monotonic trend in word-initial /1/ darkness. Thus, the lightness of word-initial /1/ could be taken as a rough proxy for the allophonic status of /1/; Figure 3 visualises this trend. Previous articulatory results from ultrasound tongue imaging suggesting that middle class Mancunians may hold a distinction gives us added confidence in this argument (Turton 2014; Turton and Baranowski 2015). The similarity of upper middle-class speech in Manchester to that found in the south of England has also been reported for GOAT-fronting (Baranowski 2017) and for the FOот-STRUT distinction (Turton and Baranowski 2020).

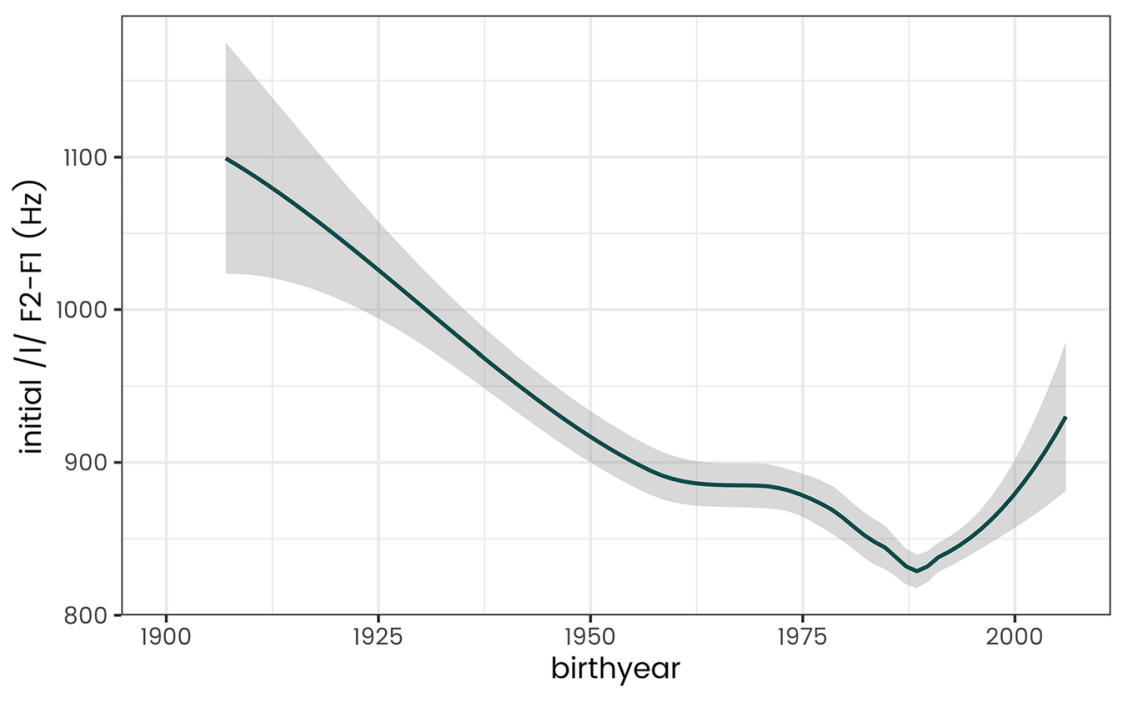

Figure 2: Initial // across year of birth (darker tokens have lower F2-F1 values). 

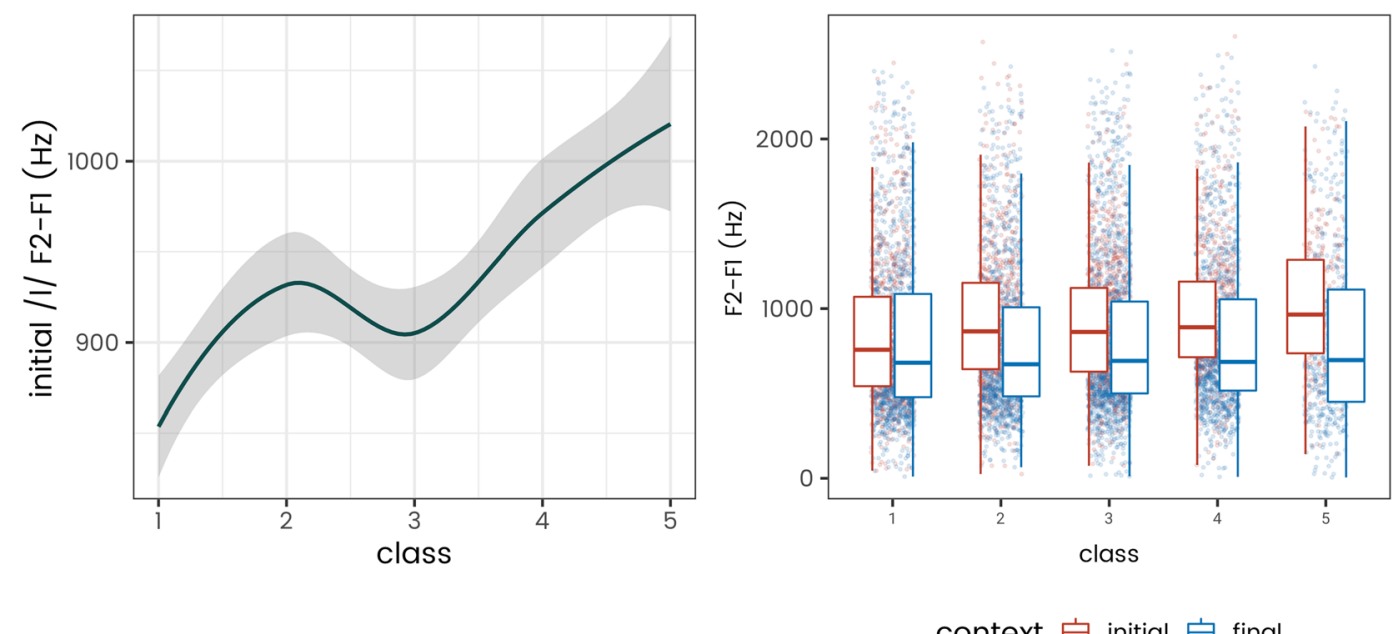

Figure 3: / $/$ in different social classes (darker tokens have lower F2-F1 values). The left panel shows initial leap-type tokens only and the right panel shows initial leap-type and final peel-type contexts (Class 1, lower working; 2, upper working; 3, lower middle; 4, middle middle; 5, upper middle).

In the left-hand panel of Figure 3, social class is plotted as a continuous predictor of the lightness of initial /1/ (lighter tokens have a larger F2-F1 difference). This visualises the monotonic relationship between social class and lightness of initial /1/. The right hand panel of Figure 3 shows initial versus final /1/s for each social class presented as factors. The figure demonstrates that the upper middle class speakers have a greater difference between initial and final contexts. Still, these initial /1/s of the upper middle class do not reach the averages of initial /l/s in young Londoners, for example, mentioned above (mean F2-F1 initial /1/ for our upper middle class Mancunians $=985 \mathrm{~Hz}$, London $=1100 \mathrm{~Hz}$ ). The lower working class show complete overlap, while the in-between classes show a small difference in the expected direction: initial tokens are lighter than final. There is a large amount of overlap between contexts, which is expected given the nature of measuring segments such as /1/ from spontaneous speech data. We tested various interactions between all pairs of social factors - birth year, class, ethnicity and gender - but none constituted a significant addition to the model. As can be seen in Table 1, females have darker /1/s than males, leading the change toward darkening. Although an interaction with class is not a significant addition, separate models on each social class find that the gender effect is much stronger in the lower working class, who has the starkest gender difference in $/ 1 /$ realisation. This may be the effect reported by Labov (2001:308); that "males in the lower social classes show a consistent pattern of retreating from or resisting a female-dominated change".

The effects of word position across different social class categories raise questions about potential change over time in the allophonic status of light and dark /l/. Recall that we posed this question earlier: is the darkening of initial /1/ over time responsible for the collapse of a previously held allophonic distinction? The results show that the data is not consistent with such an argument. There is no evidence for older speakers being more likely to have an allophonic distinction, as ascertained by comparing word-initial and word-final $/ 1 / \mathrm{s}$ in models and data visualisation. An additional model of word-final $/ 1 / \mathrm{s}$ only shows an almost identical estimate for birth year as the model for word-initial /1/ presented above: /1/ is 3-4 Hz darker with every additional birth year for both initial and final position. The overall picture is then that there is no change in the allophonic status over time, but that younger speakers are darkening all of their $/ 1 / \mathrm{s}$ across the board, that is, in all positions. Further evidence of this comes from visualising this pattern through the prism of social class (Figure 4). We pick out the two extreme classes which show this effect most clearly (the other three classes have no discernible pattern). Figure 4 demonstrates there is no change in the difference in the relationship between word-initial and word-final/1/ over time, or in other words, no change in the lack or presence of allophony over time in Manchester: both sets of lines move in parallel. 


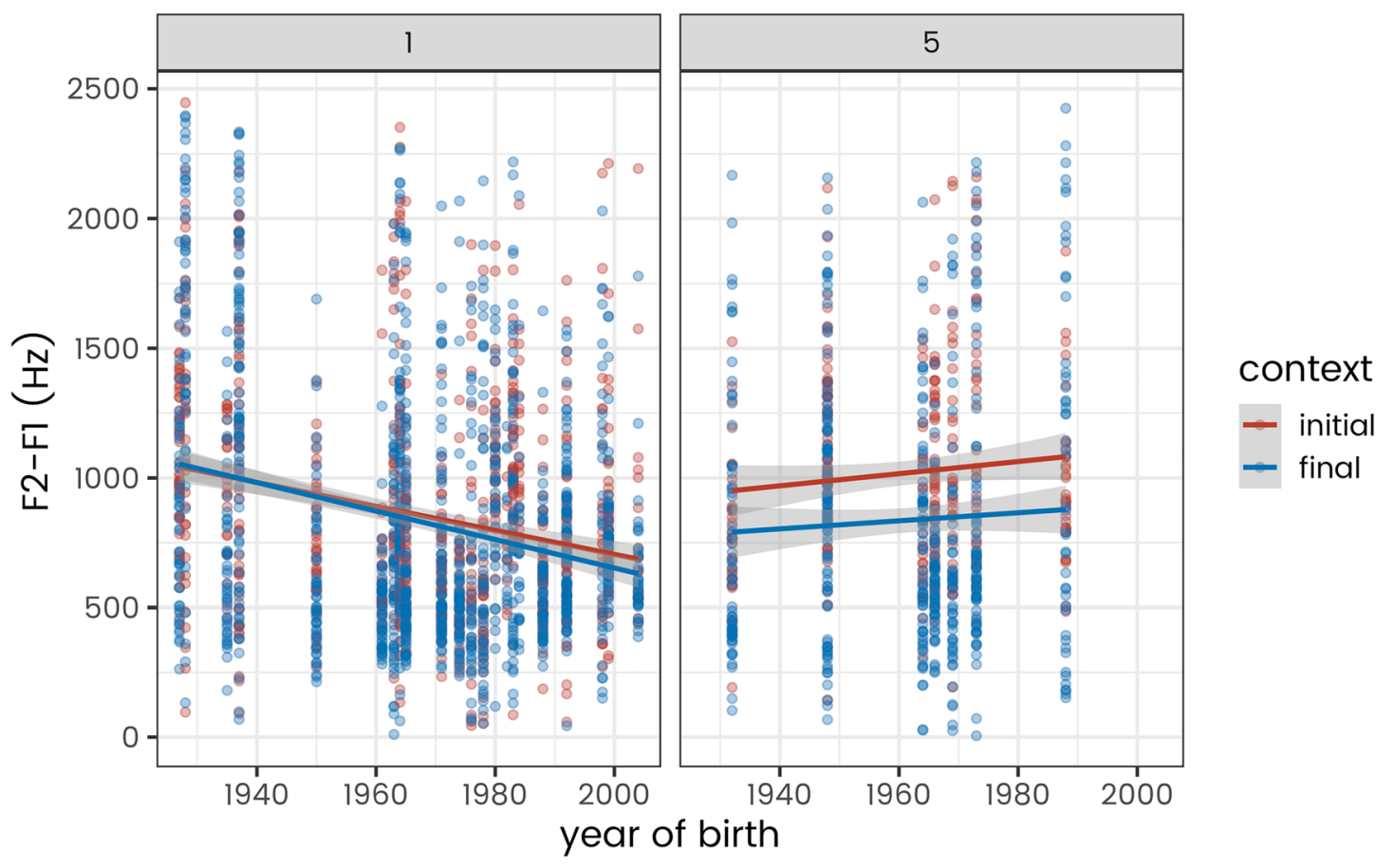

Figure 4: F2-F1 differences across age in the extreme social classes (1, lower working class; 5, upper middle class).

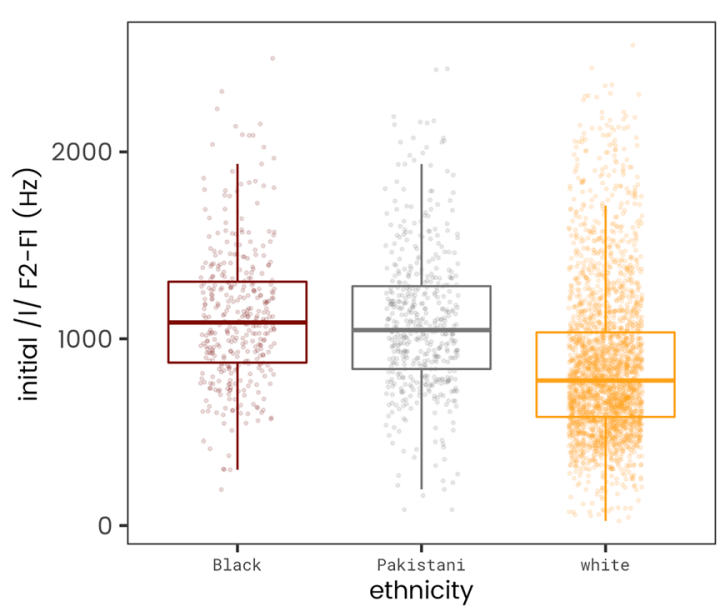

Figure 5: /l/ across ethnic groups.

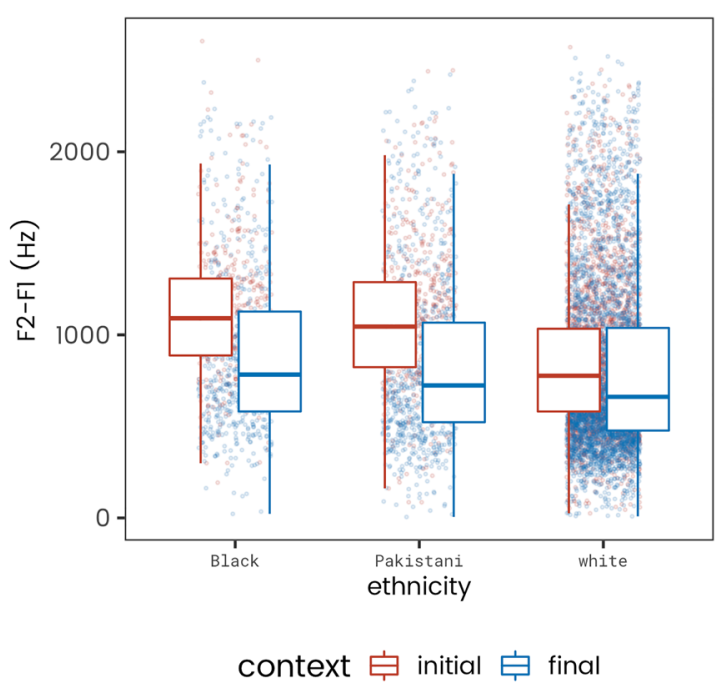

We report new results on variation in the ethnic background of our speakers in Manchester. In comparison to white speakers, Black Caribbean and Pakistani Mancunians have much lighter /1/s (Figure 5). In terms of Pakistani speakers, similar findings have been reported elsewhere in the UK: lighter /1/s in British South Asian speakers are reported in Bradford (Heselwood and McChrystal 2000; Kirkham and Wormald 2015), Glasgow (Stuart-Smith et al. 2011), and Sheffield (Kirkham 2016). These clearer variants are also found in Indian English more generally (Wells 1982; Sharma 2012). Commenting on the light realisation of /1/ in Glaswegian Asian speakers (in contrast to dark /1/s in Glaswegian in general), Stuart-Smith et al. (2011) suggest that "[c]learer realisations of /1/ could ultimately go back to Punjabi/Urdu /1/ which is typically very clear”. In reference to this, 
Kirkham (2016) notes that often speakers do not need to be proficient in a second language to acquire their multiethnic variety (see also Cheshire et al. 2011).

Interestingly, in Manchester, we note Black Caribbean Mancunians have the lightest $/ 1 / \mathrm{s}$ of all. This could also be a heritage effect, as lighter /1/s are reported for Caribbean Englishes (Wells 1982: 570). Van Hofwegen (2011) finds that lighter / $/ \mathrm{s}$ are a traditional, though receding, feature of African American English. ${ }^{2}$ Almost all of our Black speakers have either parents or relatives from Jamaica and report close links with their Caribbean heritage, including being in touch with family members from Jamaica and visiting there for holidays. At the same time, these lighter variants could also occur as a feature of Multicultural Manchester English and be available to speakers without this same heritage (Cheshire et al. 2011; Drummond 2017, 2018). The authors have noticed impressionistically that some young white working-class Mancunians in multicultural areas of the city may now have adopted this light /1/ into their own speech, although it remains to be seen if this feature is part of their vernacular or whether it is adopted in certain styles only.

A closer inspection of the data shows that younger ethnic minority speakers, both Caribbean and Pakistani, have darker /1/s than older speakers from the same ethnic background, demonstrating that all ethnic groups participate in this change (recall there is no significant interaction between age and ethnicity). Thus, even though Black youngsters have lighter laterals than their white counterparts, their $/ 1 / \mathrm{s}$ are still darker in comparison to older Black speakers. The same age pattern is true of Pakistani speakers in general, although there are some speakers who do not follow this trend. Izna L., 21 years old, upper working class, is one example of this. She has much darker /1/s than Pakistani speakers her age, more typical of white speakers. Although Izna identifies as British Pakistani and lives and attended school in a multi-ethnic area of Manchester, her mother is a white Mancunian and her friendship network is white. Izna's pattern demonstrates that further work is needed to understand this kind of variation on a micro level, and that closer attention to biracial speakers experiences (which are relatively overlooked in the existing literature; cf. Holliday 2016) is needed to understand identity patterns and parental or peer-group influence.

Both Black and Pakistani speakers, on closer inspection, do seem to have lighter word-initial $/ 1 / \mathrm{s}$ than word-final tokens. This means it is possible, in contrast to white Mancunians, that these speakers do have an allophonic distinction. The complexities of using non-controlled data to reach such conclusions are described in Turton (2014) and are best verified by further laboratory study. Nevertheless, this result provides a compelling basis for future research in multi-ethnic variation in Mancunian /1/s.
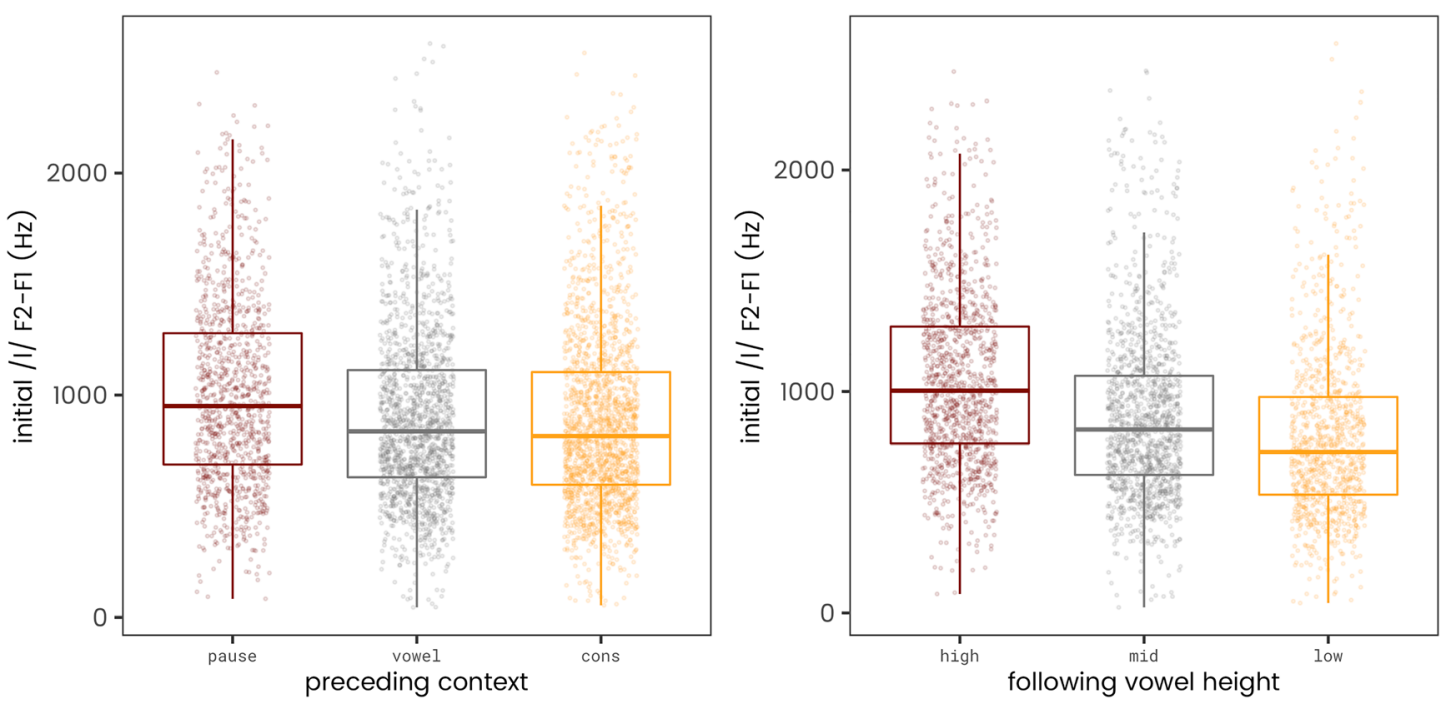

Figure 6: $/ / /$ in different phonetic contexts.

2 Interestingly, lighter variants are also found in Latino dialects in Texas (Van Hofwegen 2009) and New York City (Newman 2010). 


\subsection{Non-social factors}

In terms of linguistic and other non-social effects, the results are precisely what we would predict given what we know about coarticulation and contextual circumstances. Figure 6 shows preceding context and following vowel height side by side. The role of preceding context is clear: utterance initial /1/ is the lightest (e.g. leap over), following a vowel comes next (e.g. a leap) and following a consonant is the darkest (e.g. big leap). The right-hand panel of Figure 6 shows that initial /1/ is affected by following vowel height in the expected direction: following high vowels predict lightest /1/s (e.g. leap), followed by mid vowels (e.g. leg), with the darkest found after low vowels (e.g. last). A preceding front vowel (e.g. pill) shows lighter $/ 1 / \mathrm{s}$ than a preceding back vowel (e.g., pull), but this effect is weak and not significant in the model when everything else is taken into consideration. Duration is a significant predictor of darkness in the expected direction: darker $/ 1 / \mathrm{s}$ are longer (Lee-Kim et al. 2013; Sproat and Fujimura 1993).

\section{Conclusions}

The aim of this paper was to investigate the sociolinguistic patterning of /1/ in Manchester, a variety of English which is reported to have very dark laterals in all positions. We find that variation in word-initial $/ 1 /$ is subject to social and linguistic conditioning. The darkening of /1/ is a change in progress, with younger speakers having darker $/ \mathrm{l} / \mathrm{s}$. We demonstrate that this change in progress is not responsible for the lack of allophonic distinction reported for Mancunians in phonetic studies. This gradual shift in pronunciation also explains the discrepancy between old dialect reports, such as The linguistic Atlas of England (Orton et al. 1978) and more recent phonetic reports (Carter 2002; Kirkham 2016). /l/-darkness is conditioned by social class: the higher the social class, the lighter the initial /1/. We show that this finding could be responsible for an allophonic distinction in the highest social class, who has a much larger F2-F1 difference between initial and final contexts. At the same time, this contextual difference is acoustically much smaller when compared to accents like those in the south of England. Articulatory data from previous studies (Turton 2014; Turton and Baranowski 2015) gives us added confidence in asserting this argument despite the lack of controlled laboratory data. Finally, we find that ethnic minority speakers from Black Caribbean and Pakistani backgrounds have much lighter /1/s than white speakers. We suggest that a light /1/, relative to that of white Mancunians, may be a feature of Multicultural Manchester English. We hold back from making comments on the allophonic status of $/ 1 /$ in these speakers for the time-being. Overall, we have shown that $/ \mathrm{l} /$ is a fruitful variable for sociolinguistic study and our findings pave the way for studies of other all-dark varieties to uncover similar patterns of variation and change.

Acknowledgments: We would like to thank Ricardo Bermúdez-Otero, Josef Fruehwald, Bill Labov, Patrycja Strycharczuk and two anonymous reviewers for helpful comments and suggestions, as well as Ailís Cournane, Sophie Holmes-Elliott, Laurel MacKenzie and Meredith Tamminga.

Research funding: This research was funded by the UK Economic and Social Research Council grant ES/ I009426/1.

\section{References}

Ash, Sharon. 1982. The vocalization of / $/$ in philadelphia. Philadelphia: University of Pennsylvania PhD Dissertation.

Baranowski, Maciej. 2017. Class matters: The sociolinguistics of goose and goat in Manchester English. Language Variation and Change 29(3). 301-339.

Baranowski, Maciej \& Danielle Turton. 2018. Locating speakers in the socioeconomic hierarchy: Towards the optimal indicators of social class. In Paper presented at New Ways of Analysing Variation (NWAV) 47, 18th-21st October. New York University.

Bates, Douglas, Martin Mächler, Bolker Ben \& Steve Walker. 2015. Fitting linear mixed-effects models using Ime4. Journal of Statistical Software 67(1). 1-48. 
Beal, Joan. 2008. English dialects in the North of England: Phonology. In Bernd Kortmann \& Clive Upton (eds.), Varieties of English. Vol. 1: The British Isles, 122-144. Berlin: Mouton de Gruyter.

Bermúdez-Otero, Ricardo. 2020. The initiation and incrementation of sound change: Community-oriented momentum-sensitive learning. Glossa: A Journal of General Linguistics 5(1), 121.

Boersma, Paul \& Bruce Hayes. 2001. Empirical tests of the gradual learning algorithm. Linguistic Inquiry 32(1). 45-86.

Boersma, Paul \& David Weenink. 2017. Praat: Doing phonetics by computer, version 6.0.29. [computer program].

Britain, David. 2009. One foot in the grave. Dialect death, dialect contact, and dialect birth in England. International Journal of the Sociology of Language 2009. 121-155.

Carter, Paul. 2002. Structured variation in British English liquids. York, UK: University of York PhD Dissertation.

Cheshire, Jenny, Kerswill Paul, Sue Fox \& Eivind Torgersen. 2011. Contact, the feature pool and the speech community: The emergence of multicultural London English. Journal of Sociolinguistics 15(2). 151-196.

De Decker, Paul \& Sara Mackenzie. 2017. Tracking the phonological status of / / in Newfoundland English: Experiments in articulation and acoustics. Journal of the Acoustical Society of America 142(1). 350-362.

Drummond, Rob. 2017. (Mis) interpreting urban youth language: White kids sounding Black? Journal of Youth Studies 20(5). 640-660.

Drummond, Rob. 2018. Researching urban youth language and identity. Basingstoke: Palgrave Macmillan.

Elliott, Nancy. 2000. A sociolinguistic study of rhoticity in American film speech from the 1930s to the 1970s. Bloomington: Indiana University PhD Dissertation.

Foulkes Paul \& Gerald Docherty (eds.). 1999. Urban voices: Accent studies in the British Isles. London: Arnold.

Gick, Bryan, Fiona Campbell, Sunyoung Oh \& Linda Tamburri-Watt. 2006. Toward universals in the gestural organization of syllables: A cross-linguistic study of liquids. Journal of Phonetics 34(1). 49-72.

Hall-Lew, Lauren \& Sonya Fix. 2012. Perceptual coding reliability of (l)-vocalisation in casual speech data. Lingua 122. 794-809.

Heselwood, Barry \& Louise McChrystal. 2000. Gender, accent features and voicing in Panjabi-English bilingual children. Leeds Working Papers in Linguistics and Phonetics 8. 45-70.

Holliday, Nicole R. 2016. Intonational variation, linguistic style and the Black/Biracial experience. New York: New York University PhD Dissertation.

Horvath, Barbara M. \& Ronald J. Horvath. 2001. A multilocality study of a sound change in progress: The case of /// vocalization in New Zealand and Australian English. Language Variation and Change 13(1). 37-57.

Horvath, Barbara M. \& Ronald J Horvath. 2002. The geolinguistics of /l/-vocalization in Australia and New Zealand. Journal of Sociolinguistics 6(3). 319-346.

Johnson, Wyn \& David Britain. 2007. L-vocalisation as a natural phenomenon: Explorations in sociophonology. Language Sciences 29(2). 294-315.

Kelly, John \& John Local. 1986. Long-domain resonance patterns in English. In Institute of Electronic Engineers: Proceedings of the International Conference on Speech Input/Output, 304-308.

Khattab, Ghada. 2002. / / production in English-Arabic bilingual speakers. International Journal of Bilingualism 6(3). $335-353$.

Khattab, Ghada. 2011. Acquisition of Lebanese Arabic and Yorkshire English /l/ by bilingual and monolingual children. Amsterdam: John Benjamins.

Kirkham, Sam. 2016. Ethnicity and phonetic variation in Sheffield English liquids. Journal of the International Phonetic Association 47(1). 17-35.

Kirkham, Sam. 2020. A typology of laterals in twelve English dialects. https://osf.io/mvjw3 (accessed 25 June 2020).

Kirkham, Sam, Claire Nance, Bethany Littlewood, Kate Lightfoot \& Eve Groarke. 2019. Dialect variation in formant dynamics: The acoustics of lateral and vowel sequences in Manchester and Liverpool English. Journal of the Acoustical Society of America 145. 784-794.

Kirkham, Sam, Danielle Turton \& Leemann Adrian. 2020. A typology of laterals in twelve English dialects. Journal of the Acoustical Society of America 148(1). EL72-EL76.

Kirkham, Sam \& Jessica Wormald. 2015. Acoustic and articulatory variation in British Asian English liquids. In The Scottish Consortium for ICPhS 2015 (ed.), Proceedings of the 18th international congress of phonetic sciences. Glasgow, UK: The University of Glasgow.

Labov, William. 1984. Field methods of the project on linguistic change and variation. In Baugh John \& Sherzer Joel. (eds.), Language in use: Readings in sociolinguistics, 28-66. Englewood Cliffs, NJ: Prentice-Hall.

Labov, William. 2001. Principles of linguistic change: Social factors. Oxford: Blackwell.

Lee-Kim, Sang-Im, Lisa Davidson \& Sangjin Hwang. 2013. Morphological effects on the darkness of English intervocalic /I/. Laboratory Phonology 4(2). 475-511.

Lehiste, Ilse. 1964. Acoustical characteristics of selected English consonants. Indiana Research Centre in Anthropology, Folklore and Linguistics 34. 10-50.

Morris, Jonathan. 2013. Sociolinguistic variation and regional minority language bilingualism: An investigation of Welsh-English bilinguals in North Wales. Manchester: University of Manchester PhD Dissertation.

Morris, Jonathan. 2017. Sociophonetic variation in a long-term language contact situation: /l/-darkening in Welsh-English bilingual speech. Journal of Sociolinguistics 21(2). 183-207. 
Nance, Claire. 2013. Phonetic variation, sound change, and identity in Scottish Gaelic. Glasgow: University of Glasgow PhD Dissertation.

Nance, Claire. 2020. Bilingual language exposure and the peer group: Acquiring phonetics and phonology in Gaelic Medium Education. International Journal of Bilingualism 24(2). 360-375.

Newman, Michael. 2010. Focusing, implicational scaling, and the dialect status of New York Latino English. Journal of Sociolinguistics 14(2). 207-239.

Orton, Harold. 1962. Survey of English dialects (a): Introduction. London; New York: Routledge.

Orton, Harold, Stewart Sanderson \& John Widdowson (eds.). 1978. The linguistic atlas of England. London: Croom Helm.

Pratt, Teresa. 2020. Embodying “tech": Articulatory setting, phonetic variation, and social meaning. Journal of Sociolinguistics 24(3). 328-349.

Rosenfelder, Ingrid, Josef Fruehwald, Keelan Evanini, Seyfarth Scott, Kyle Gorman, Hilary Prichard \& Jiahong Yuan. 2014. FAVE 1.1.3. ZENODO.

Sharma, Devyani. 2012. Stylistic activation in ethnolinguistic repertoires. University of Pennsylvania Working Papers in Linguistics 18(2). 15.

Sproat, Richard \& Osamu Fujimura. 1993. Allophonic variation in English /// and its implications for phonetic implementation. Journal of Phonetics 21. 291-311.

Stoddart, Jana, Clive Upton \& John Widdowson. 1999. Sheffield dialect in the 1990s: Revisiting the concept of NORMs. In Paul Foulkes \& Gerald Docherty (eds.), Urban voices: Accent studies in the British Isles, 72-89. London: Arnold.

Strycharczuk, Patrycja, Donald Derrick \& Jason Shaw. 2020. Locating de-lateralization in the pathway of sound changes affecting coda /I/. Laboratory Phonology. Journal of the Association for Laboratory Phonology 11(1). 21.

Stuart-Smith, Jane, Claire Timmins \& Farhana Alam. 2011. Hybridity and ethnic accents: A sociophonetic analysis of "Glaswasian". Selected Papers ICLaVE Amsterdam: Benjamins 5. 43-57.

Tagliamonte, Sali. 2006. Analysing sociolinguistic variation. Cambridge: Cambridge University Press.

Tagliamonte, Sali \& Alexandra D’Arcy. 2009. Peaks beyond phonology: Adolescence, incrementation, and language change. Language 85(1). 58-108.

Tollfree, Laura F. 1999. South-east London English: Discrete versus continuous modelling of consonantal reduction. In Paul Foulkes \& Gerald Docherty (eds.), Urban voices: Accent studies in the British Isles, 163-184. London: Arnold.

Turton, Danielle. 2014. Variation in English /l/: Synchronic reflections of the life cycle of phonological processes. Manchester: University of Manchester PhD Dissertation.

Turton, Danielle. 2017. Categorical or gradient? An ultrasound investigation of / //-darkening and vocalisation in varieties of English. Laboratory Phonology 8(1). https://doi.org/10.5334/labphon.35.

Turton, Danielle \& Maciej Baranowski. 2015. Absence of a blocking r[y]l?: The presence of / $\mathrm{u}$-fronting before /l/ in Manchester. In Paper given at UKLVC, University of York, 1st-3rd September 2015.

Turton, Danielle \& Maciej Baranowski. 2020. Not quite the same: The social and phonetic conditioning of the Foot-Strut vowels in Manchester. Journal of Linguistics 57(1). 163-201.

Van Hofwegen, Janneke. 2009. Cross-generational change in / / in Chicano English. English world-wide 30(3). 302-325.

Van Hofwegen, Janneke. 2011. Apparent-time evolution of /// in one African American community. Language Variation and Change 22(03). 373-396.

Wells, John C. 1982. Accents of English. Cambridge: Cambridge University Press.

Yuan, Jiahong \& Mark Liberman. 2009. Investigating / / variation in English through forced alignment. In INTERSPEECH 2009: 10th annual conference of the international speech communication association, Brighton, UK, 6-10 September 2009, 2215-2218.

Yuan, Jiahong \& Mark Liberman. 2011. /l/ variation in American English: A corpus approach. Journal of Speech Sciences 1(2). 35-46. 